\title{
Mediators of the Link Between Autistic Traits and Relationship Satisfaction in a Non-Clinical Sample
}

\author{
Monique M. H. Pollmann • Catrin Finkenauer • \\ Sander Begeer
}

Published online: 3 November 2009

(C) The Author(s) 2009. This article is published with open access at Springerlink.com

\begin{abstract}
People with ASD have deficits in their social skills and may therefore experience lower relationship satisfaction. This study investigated possible mechanisms to explain whether and how autistic traits, measured with the AQ, influence relationship satisfaction in a non-clinical sample of 195 married couples. More autistic traits were associated with lower relationship satisfaction for husbands but not for wives. Multiple mediation analyses revealed that husbands' responsiveness towards their wives, trust, and intimacy mediated this link between autistic traits and relationship satisfaction. These findings suggest that autistic traits may hamper men's relationship satisfaction because they impede relationship-specific feelings and behavior. There was no partner-effect of autistic traits, indicating that more autistic traits do not necessarily influence the partner's perceptions of relationship satisfaction.
\end{abstract}

Keywords Autism - AQ - Relationship satisfaction · Relationship well-being $\cdot$ Multiple mediation

M. M. H. Pollmann · C. Finkenauer

Department of Social Psychology, VU University Amsterdam,

Amsterdam, The Netherlands

S. Begeer

Department of Developmental Psychology, VU University

Amsterdam, Amsterdam, The Netherlands

M. M. H. Pollmann ( $₫)$

Department of Social Psychology, Faculteit Sociale

Wetenschappen, Tilburg University, PO Box 90153,

5000 Tilburg, The Netherlands

e-mail: m.m.h.pollmann@uvt.nl

\section{Introduction}

People with autism spectrum disorders (ASD) have deficits in their social and communicative skills and face difficulties in their social relationships. Despite these problems, the majority of people with ASD do not want to be socially excluded (Bauminger et al. 2003; Rutgers et al. 2004) and show similar desires for intimate relationships as typically developing individuals (Hellemans et al. 2007; Henault 2005; Orsmond et al. 2004). Establishing and maintaining successful intimate relationships are essential elements of a happy and healthy life (Baumeister and Leary 1995). Although we cannot be sure whether individuals with and without ASD depend on relationships to the same extent and in the same way (Baron-Cohen and Wheelwright 2003; Kelly et al. 2008), research shows that social support greatly enhances the quality of life of people with ASD (Renty and Roeyers 2006, 2007; Weidle et al. 2006; Hillier et al. 2007), and that family conflict increases anxiety and depression in children with ASD (Kelly et al. 2008). This research highlights the importance of well-functioning relationships for individuals with ASD. It is not clear, however, to what extent they are able to maintain satisfying intimate relationships and how their social difficulties affect their satisfaction with close relationships. It is equally unclear whether autistic traits affect relationship satisfaction in non-clinical samples. The present paper tries to answer the latter question by examining the link between autistic traits and relationship satisfaction in a non-clinical sample and investigating possible mediators of this link. We acknowledge that the broader autism phenotype, measured in a non-clinical sample, is not interchangeable with a clinical diagnosis of ASD. However, studying the severity of autistic traits in the current large sample of couples will be informative on the links between the 
broader autistic phenotype and relationship satisfaction. Moreover, in clinical samples, autism is increasingly conceived of as a continuum. Taking account of the severity of the disorder has proven valuable for research (Gotham et al. 2009), and the fifth version of the DSM is even likely to adopt a dimensional approach to autism (Lord 2009). Furthermore, several studies by independent research groups indicate that characteristics of the autism phenotype can be measured reliably using quantitative scales (BaronCohen et al. 2001; Constantino et al. 2003) and that autistic traits may follow a continuous distribution in the general population (Constantino and Todd 2003; Hoekstra et al. 2008).

Are Autistic Traits Associated with Relationship Satisfaction?

Most research on social relationships of people with a clinical diagnosis of ASD has focused on children's relationships with peers (Bauminger et al. 2003; Orsmond et al. 2004). Only recently researchers started examining autistic traits in romantic relationships in adult samples, both clinical and non-clinical. For example, adults with ASD reported lower romantic functioning-operationalized as self-reported desire, knowledge, and experience with intimate relationships-than non-autistic controls (Stokes et al. 2007). Moreover, the severity of husbands' autistic disorder is negatively correlated with relationship satisfaction as reported by the wife, underlining the potential relational impact of ASD (Renty and Roeyers 2007).

In non-clinical samples, individuals with many autistic traits were as likely to be in a romantic relationship as individuals with fewer autistic traits. However, individuals with many autistic traits reported relatively more general loneliness than those with fewer autistic traits (Jobe and Williams White 2007). This finding is a first indication that, compared to relationships of people with few autistic traits, relationships of people with many autistic traitseven in a non clinical sample-may not be as satisfying. Considering the centrality of satisfying relationships for psychosocial well-being (e.g. Baumeister and Leary 1995), investigating how autistic traits may contribute to relationship satisfaction, and possibly lead to a decrease in relationship satisfaction, is particularly important.

\section{How Do Autistic Traits Affect Relationship Satisfaction?}

Researchers on close relationships recognize that relationship quality varies as a function of both people's individual dispositions and their relationship-specific behavior and feelings (e.g. Holmes and Rempel 1989). First, findings from dispositional (person-centered) research showed that relationship satisfaction corresponds with higher selfesteem and a secure attachment style (Bowlby 1982; Hendrick et al. 1988; Jones and Cunningham 1996). ASD has been related to both lower ratings of global self-worth (Capps et al. 1995) and a less secure attachment style (Rutgers et al. 2004).

Second, relationship-centered studies found that relationship satisfaction is linked to relationship-specific behavior. Specifically, responsiveness towards the partner's needs, including understanding, validating, and caring for the partner (e.g. Reis 2007; Reis and Shaver 1988), and the disclosure of personal information to the partner, including sharing feelings and thoughts (Dindia and Timmerman 2003), are strong predictors of relationship satisfaction. ASD is defined by a lack of spontaneous sharing of pleasure, interests, or achievements with other people (American Psychiatric Association 1994), poor perception of others' emotions and internal states (Begeer et al. 2008), and a limited use of communication for social purposes such as seeking comfort (Rubin and Lennon 2004).

Third, research on relationship-specific feelings suggests that relationship satisfaction develops as feelings of intimacy and trust between partners increase. Not surprisingly, intimacy and trust are considered to be the most important ingredients for happy, well-functioning romantic relationships (e.g. Reis and Shaver 1988; Simpson 2007). Children with autism tend to rate their friendships as lower on the dimension of security-intimacy and trust than typically developing children (Bauminger et al. 2003). This may also be the case for intimate relationships of adults with many autistic traits. In sum, findings on individual dispositions and on relationship-specific behavior and feelings suggest that people with more autistic traits should be less satisfied with their relationship.

Because close relationships by definition involve two partners, people's autistic traits may also influence the relationship satisfaction of their partner (cf. Renty and Roeyers 2007). The present research examines both actor (i.e. the person with autistic traits) and partner effects of autistic traits on relationship satisfaction.

\section{The Current Research}

The present paper is the first to investigate the link between relationship satisfaction and autistic traits in a non-clinical sample. We hypothesized that individuals with more autistic traits are less satisfied with their relationship than individuals with fewer autistic traits. Importantly, we investigated whether individual dispositions (i.e. selfesteem, attachment style) and relationship-specific behavior (i.e. responsiveness, disclosure) and feelings (i.e. intimacy, trust) mediate the link between autistic traits and 
relationship satisfaction. Because we did not have a priori hypotheses which of these mediators will be strongest, we used a multiple mediation approach (Preacher and Hayes 2008). This approach allowed us to test different mediators simultaneously and to directly compare the strength of each indirect effect. We tested our hypotheses in a nonclinical sample of 195 newlywed couples. Including both spouses allowed us to investigate whether autistic traits influence people's own perception of relationship satisfaction (i.e. actor effect) and whether autistic traits influence their partner's perception of relationship satisfaction (i.e. partner effect), and whether gender modulates these effects.

\section{Method}

The data used for this study are derived from Wave 2 of "The Search for Inter-Personal Accuracy Project", a longitudinal study among newlywed couples (Finkenauer 2006). This study investigates the influence of personal dispositions, behavior in the relationship, and partner perception on marital well-being in the first 3 years of marriage. Participants received a large battery of questionnaires to fill out under supervision of a trained interviewer. Only scales relevant to the present manuscript are described below. For a more detailed description of the study, see (Finkenauer et al. 2009).

\section{Participants}

Participants were 195 of the 199 original newlywed couples who participated in the second wave of a longitudinal study. Wave 2 was conducted on average 10 month after the couple got married. At the time of the second wave husbands' mean age was 33.05 years $(\mathrm{SD}=4.86)$ and wives' mean age was 30.11 years $(\mathrm{SD}=4.25)$. Couples had been romantically involved for an average of 6.88 years $(\mathrm{SD}=3.10)$, and had been living together for an average of 4.62 years $(S D=2.26)$. Nearly all of the couples $(98.5 \%$ of the husbands and $96.4 \%$ of the wives) were Dutch.

\section{Procedure and Measures}

Both members of the couple separately filled out an extensive questionnaire at home in the presence of a trained interviewer. The questionnaire took about $90 \mathrm{~min}$ to complete. Partners were instructed not to discuss the questions or answers with each other. Each couple received 15 Euros and a book after they completed the questionnaire. Only scales that are relevant for the present investigation are described below.
Autism Spectrum Quotient (AQ)

We used a Dutch, abridged version of the AQ (BaronCohen et al. 2001) to measure autistic traits. The construction and validation of the AQ-short is described in detail in Hoekstra et al. (2009). Unlike the original 4-point scale with a binary scoring system, we used a 5-point scale $(1=$ not at all; $5=$ very $m u c h)$ and average scores to attain a higher level of differentiation among responses. Higher scores represent more autistic traits. Internal consistency of the AQ-short was good for husbands and wives $(\alpha=.73$ and .75 , respectively).

\section{Relationship Satisfaction}

We measured relationship satisfaction using the Dyadic Adjustment Scale (DAS). This scale taps components of couple functioning such as agreement regarding important values (religion, decision making), satisfaction, conflict management, and expressions of love and affection (Spanier 1976; e.g. "How often do you think things are going well between you and your husband?"; $0=$ never, $5=$ all the time). It is widely accepted as a measure of relationship satisfaction and has been used in research on relationship satisfaction of men with ASD (Renty and Roeyers 2007). Summed scores indicate overall dyadic adjustment with higher scores representing better relationship satisfaction. Reliability was good for husbands and wives $(\alpha=.87$ and .86 , respectively).

\section{Mediators}

Self-esteem was measured using the Rosenberg self-esteem questionnaire (Rosenberg 1965). This scale consists of 10 items, measuring how satisfied participants are with themselves (e.g. "On the whole, I am satisfied with myself"; 1 = do not agree at all, $5=$ completely agree). Higher scores indicate higher self-esteem. Reliability of the scale was good for husbands and wives $(\alpha=.86$ and $\alpha=.84$, respectively).

Attachment was measured using a shortened version of the Experiences in Close Relationships Questionnaire (Brennan et al. 1998). Of the 36 original items, we selected 22 items to measure insecure attachment. Participants rated to what extent they agree with statements like: "I worry a lot about my relationships" $(1=$ do not agree at all, $5=$ completely agree). Higher scores indicate a less secure attachment style. Reliability of the scale was good $(\alpha=.86$ for husbands and $\alpha=.84$ for wives).

Disclosure was measured with the relationship-specific self-disclosure scale (Finkenauer et al. 2004) consisting of seven items that ask whether specific topics are shared with the partner, (e.g. "I share my most intimate feelings with 
my partner"; $1=$ do not agree at all, 5= completely agree). Ratings were given on a 5-point-scale, with higher scores representing more relationship-specific disclosure. Reliability of the scale was good ( $\alpha=.89$ for husbands and wives).

Responsiveness was measured with an 18 items scale (e.g. Birnbaum and Reis 2006), ratings are given on a 5-point scale with higher scores representing more responsiveness (e.g. "I am an excellent judge of my partner's character"; $1=$ do not agree at all, $5=$ agree completely). Reliability of the responsiveness scale was good $(\alpha=.89$ for husbands and $\alpha=.90$ for wives).

Intimacy was measured using the intimacy subscale of the Perceived Relationship Quality Components (Fletcher et al. 2000). This subscale consists of 3 items, ratings are given on 5-point scales and higher ratings indicated greater intimacy (e.g. "How intimate is your relationship?"; $1=$ not at all, $5=$ completely). Reliability of the scale was good for husbands and wives $(\alpha=.85$ and $\alpha=.83$, respectively).

Partner-specific trust was measured with a scale consisting of 12 items (Rempel and Holmes 1986). Ratings are given on 5-point scales with higher scores representing more trust (e.g. "I can count on my wife to keep the promises she made"; $1=i$ s not at all true, $5=$ is completely true). Reliability of the scale was good for husbands and wives ( $\alpha=.84$ and $\alpha=.82$, respectively).

\section{Results}

\section{Descriptive Statistics}

Table 1 provides the descriptive statistics for husbands and wives and a comparison of their means for all variables relevant to this investigation.

On average, both husbands and wives were very satisfied with their relationship, and did not differ in their level of satisfaction. In line with earlier findings, husbands report more autistic traits than wives (Baron-Cohen et al. 2001).
Furthermore, husbands scored higher on self-esteem than wives, and wives scored higher on self-disclosure than husbands, which is consistent with the existing literature (Kling et al. 1999; Finkenauer et al. 2004). No other differences were found between husbands and wives.

Table 2 provides the intercorrelations of the AQ-short, relationship satisfaction, and the assessed mediators for husbands and for wives. As can be seen, the score on the AQ-short is significantly negatively related to relationship satisfaction for husbands but not for wives. For both husbands and wives the AQ score is significantly related to all the possible mediators in the expected directions at a significance level of at least $p<.05$. Although not corrected for the number of tests performed, these correlations are a first indication that autistic traits may reduce relationship satisfaction, at least for husbands, and that the proposed mediators may play a role in this link. Moreover, although not directly related to our research question, it may be noteworthy that we find positive correlations between partners' scores on all variables except the AQ-short scores and self-esteem.

\section{Are Autistic Traits Related to Relationship Satisfaction?}

To investigate whether people with more autistic traits are less satisfied with their relationship, we used hierarchical linear modeling because the data from two spouses of a couple are non-independent. We included gender into the model as possible moderator of the effect, because husbands' and wives' AQ-short scores differed significantly, and controlled for relationship duration. The analysis revealed a negative relation between autistic traits and relationship satisfaction, $\beta=-.48, t=2.40, p<.05$, and a significant interaction with gender, $\beta=.19, t=1.98$, $p<.05$. In order to identify the nature of this interaction we performed separate regression analyses for husband and wives, controlling for relationship duration. For husbands, the link between autistic traits and satisfaction was
Table 1 Means, standard deviations (in brackets), and pairwise comparison of husbands and wives scores on all assessed variables

The range of the scales is given in brackets behind the name of the scale

$* p<.05 ; * * p<.01$;

$* * * p<.001$

\begin{tabular}{lccl}
\hline & Husbands & \multicolumn{1}{l}{ Wives } & Comparison \\
\hline Relationship satisfaction (0-141) & $111.89(9.84)$ & $110.39(10.94)$ & $t(1,194)=1.42$ \\
AQ-short (1-5) & $2.55(0.30)$ & $2.42(0.29)$ & $t(1,194)=4.46^{* * *}$ \\
Mediators & & & \\
Self-esteem (1-5) & $4.17(0.47)$ & $4.00(0.45)$ & $t(1,194)=3.72^{* * *}$ \\
Attachment (1-5) & $1.76(0.40)$ & $1.78(0.38)$ & $t(1,189)=0.76$ \\
Responsiveness (1-5) & $4.17(0.37)$ & $4.20(0.37)$ & $t(1,193)=0.76$ \\
Disclosure (1-5) & $4.18(0.58)$ & $4.37(0.49)$ & $t(1,191)=3.86^{* * *}$ \\
Intimacy (1-5) & $4.50(0.50)$ & $4.51(0.47)$ & $t(1,193)=0.17$ \\
Trust (1-5) & $4.22(0.44)$ & $4.19(0.45)$ & $t(1,194)=0.71$ \\
\hline
\end{tabular}


Table 2 Intercorrelations of the AQ-short score, relationship satisfaction, and the possible mediators

\begin{tabular}{|c|c|c|c|c|c|c|c|c|}
\hline & 1. & 2. & 3. & 4. & 5. & 6. & 7. & 8. \\
\hline 1. AQ-short & .03 & $-.30^{* *}$ & $-.41^{* *}$ & $.34^{* *}$ & $-.25^{* *}$ & $-.24 * *$ & $-.21^{* *}$ & $-.27^{* *}$ \\
\hline 2. Relationship satisfaction & -.09 & $.32 * *$ & $.37^{* *}$ & $-.63^{* *}$ & $.67^{* * *}$ & $.47^{* *}$ & $.61 * *$ & $.65^{* *}$ \\
\hline 3. Self-esteem & $-.34 * *$ & $.30 * *$ & .00 & $-.57^{* *}$ & $.32 * *$ & $.24 * *$ & $.26 * *$ & $.42^{* *}$ \\
\hline 4. Attachment & $.25 * *$ & $-.57 * *$ & $-.42 * *$ & $.32 * *$ & $-.65^{* *}$ & $-.58 * *$ & $-.52 * *$ & $-.70 * *$ \\
\hline 5. Responsiveness & $-.20 * *$ & $.45^{* *}$ & $.29 * *$ & $-.60 * *$ & $.28 * *$ & $.50 * *$ & $.65^{* *}$ & $.70^{* *}$ \\
\hline 6. Disclosure & $-.17 *$ & $.37 * *$ & $.21 * *$ & $-.56^{* *}$ & $.53 * *$ & $.17 *$ & $.36^{* *}$ & $.45^{* *}$ \\
\hline 7. Intimacy & $-.15^{*}$ & $.50 * *$ & $.18^{*}$ & $-.50 * *$ & $.64 * *$ & $.44 * *$ & $.28 * *$ & $.54 * *$ \\
\hline 8. Trust & $-.16^{*}$ & $.54 * *$ & $.32 * *$ & $-.68 * *$ & $.67 * *$ & $.42 * *$ & $.48 * *$ & $.21 * *$ \\
\hline
\end{tabular}

Correlations above the diagonal represent correlations for husbands; correlations under the diagonal represent correlations for wives; correlations on the diagonal (in bold) represent correlations between spouses. No corrections for the number of tests performed were made

$* p<.05 ; * * p<.01$

significant and negative, $\beta=-.29, t=4.22, p<.001$, whereas for wives, the link was non-significant, $\beta=-.09$, $t=1.17, p>.05$. Thus, husbands who report more autistic traits are less satisfied with their relationship than husbands who posses fewer autistic traits. Wives with more autistic traits, however, are not less satisfied with their relationship than wives with fewer autistic traits.

To investigate whether autistic traits of one partner influence the relationship satisfaction of the other partner (i.e. partner effects), we designed a hierarchical linear model with the AQ-short score of one partner predicting the other partner's relationship satisfaction, again controlling for gender and relationship duration. We found no main effect of AQ-short score on the partner's relationship satisfaction, $\beta=-.18, t=0.97, p>.05$, nor an interaction effect with gender, $\beta=.10, t=1.05, p>.05$. Thus, partners of both men and women with more autistic traits do not report lower relationship satisfaction than partners of people with fewer autistic traits.

\section{Mediators of the Link between Autistic Traits and Relationship satisfaction}

To investigate why husbands with more autistic traits report lower relationship satisfaction, we performed a multiple mediator analysis that allows us to compare the strength of the six mediators included in the present investigation (Preacher and Hayes 2008). This bootstrapping analysis does not rely on the assumption of a normal sampling distribution and reduces the likelihood of Type 1 error by minimizing the number of inferential tests (Preacher and Hayes 2008). This analysis disentangles the total effectthe effect of the independent variable on the dependent variable, not considering the mediators-into the direct effect-the effect of the independent variable on the dependent variable, controlled for the mediators-and the indirect effect - the effect via the mediators.
Because there was no link between AQ-short and relationship satisfaction for wives, we conducted this mediation analysis for husbands only. Figure 1 provides an overview of the effects of the AQ-short and the mediators on husbands' relationship satisfaction.

First, a significant total effect of autistic traits on relationship satisfaction emerged, $\beta=-.34, \quad t=4.73$, $p<.01$. When dividing this total effect into the direct effect of the autistic traits and the total indirect effects of all mediators combined, the direct effect of the autistic traits is no longer significant, $\beta=-.09, t=1.57, p>.05$, but the total indirect effect is significant, $\beta=-.25$, $t=4.37, p<.01$. Because the difference between the total effect and the direct effect of the autistic traits is different from zero, we can conclude that the effect of autistic traits on relationship satisfaction is mediated by the proposed mediators (Preacher and Hayes 2008). The total indirect effect can be further divided into the indirect effects of each of the mediators. The mediators that significantly contributed to the indirect effect were responsiveness, intimacy, and partner-specific trust (Fig. 1). More autistic traits among men thus seem to hamper relationship-specific behavior and feelings which, in turn, reduce their relationship satisfaction.

\section{Discussion}

In the present paper we investigated whether autistic traits are related to relationship satisfaction and how this relation can be characterized. We found that men with more autistic traits report less relationship satisfaction. This effect was not found for women. Furthermore, the partner's autistic traits were not related to people's relationship satisfaction, neither for men nor women. Importantly, we additionally investigated the specific process by which autistic traits may be associated with relationship satisfaction. 
Fig. 1 Multiple mediation analysis of AQ and relationship satisfaction for husbands. The top diagram displays the total effect of the AQ on relationship satisfaction. The bottom diagram displays the direct effect of the AQ and the indirect effect through all the mediators. $* p<.05 ; * * p<.01$
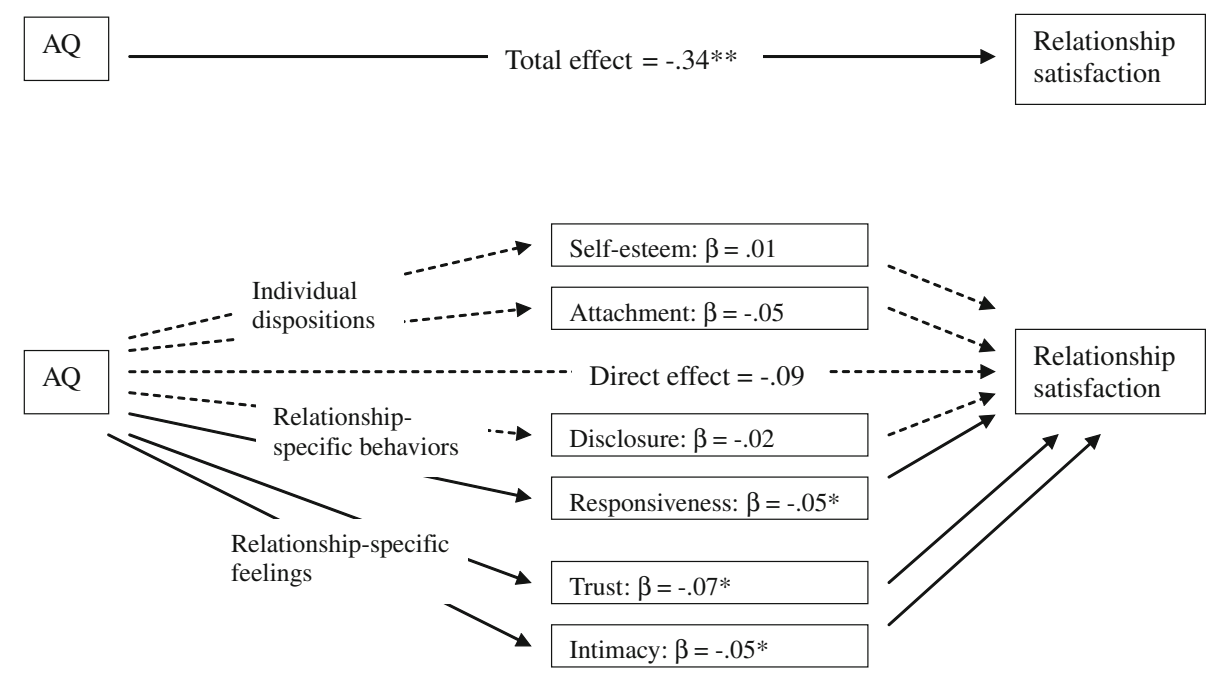

Mediators of the Link Between Autistic Traits and Relationship Satisfaction

The link between autistic traits and relationship satisfaction among male participants was mediated by responsiveness towards the partner, trust in the partner, and intimacy in the relationship. Having more autistic traits thus appears to reduce men's relationship satisfaction mainly because of relationship-specific factors. Responsiveness represents understanding, validation and caring for the partner, which are seen as key factors to build up intimacy and trust in the relationship (Reis and Shaver 1988). Our findings suggest that men who report more autistic traits have the feeling that they lack this intimacy or that they can not trust their partner, which translates into the feeling that the relationship is less satisfying.

It is noteworthy that dispositional measures, such as self-esteem and attachment, did not function as mediators. One could argue that this finding is an artifact of the correspondence principle (e.g. Ajzen and Fishbein 1977). This principle suggests that links between variables may be stronger if the specificity of the predictor and criterion match. In our study, the relationship-specific measures are by definition a better match to relationship satisfaction than dispositional measures and may therefore have had an advantage over dispositional measures. Nevertheless, the $\mathrm{AQ}$-short too is a dispositional measure and the relationship-specific measures were all consistently related to the AQ-short. Furthermore, all proposed mediators correlated with both the AQ-short and relationship satisfaction. Yet, only the relationship-specific measures emerged as mediators. Our data therefore nicely distinguishes between factors that are merely related to both constructs and factors that can explain why people with autistic traits are less satisfied with their relationship.
It is also possible that more complex models are applicable whereby high AQ is related to low self-esteem, which in turn translates in lower responsiveness, which then leads to lower relationship functioning. More studies are needed to investigate the processes underlying dispositional and relationship-specific variables.

The cross-sectional nature of this study does not allow us to draw strong conclusions about the causal direction of the mediating effect. We argued that men who report autistic traits report lower relationship functioning because they feel that the relationship is less intimate. It is equally possible however, that because they experience their relationship as less well-functioning, they withdraw from it and therefore perceive it as less intimate. Furthermore, it should be noted that despite its merits, the AQ remains a selfreport measure of the autistic traits. Prospective studies, including individuals with a clinical diagnosis of autism, are needed to illuminate the causal directions and the generalizability of effects.

\section{Subjectivity of Reduced Marital Functioning}

It is important to note that we did not find partner effects, that is, partners of people with more autistic traits did not report lower relationship satisfaction than partners of people with fewer autistic traits. This finding is inconsistent with research using clinical samples that shows that wives of men with ASD report lower relationship satisfaction (Renty and Roeyers 2007). In our non-clinical sample, husbands' reduced relationship satisfaction and relationship-specific feelings are not shared by their wives. Maybe autistic traits only have a noticeable impact on the relationship if they reach clinical levels. It is possible that wives simply perceive husbands with higher scores on the AQ (but still non-clinical) as being "typical male." 
According to the extreme male brain theory of autism (Baron-Cohen 2002) men engage in more systemizing and less empathizing, and autism can be seen as an extreme form of this profile. Therefore men with more autistic traits may report less responsiveness, but rather than perceiving this lack of responsiveness as negative wives may experience it as the default.

The finding that the wives' relationship satisfaction is not influenced by husbands' score on the AQ is especially surprising because responsiveness, trust, and intimacy describe reciprocal processes between partners. That is, because one partner is responsive, the other partner feels more trust, which enhances intimacy (e.g. Wieselquist et al. 1999). If husbands who score higher on the AQ were indeed less responsive this should have affected wives' perception. Although men with more autistic traits reported less responsiveness towards their wives, they may not necessarily behave in a less responsive way than men with fewer autistic traits. Alternatively, men with fewer autistic traits may have overestimated their real-life responsiveness. This suggestion is consistent with findings on individuals with clinical ASD, who show enhanced analytic abilities and a stronger correlation between social understanding and behavior than typically developing controls (Travis et al. 2001; De Martino et al. 2008).

For women there was no link between autistic traits and relationship satisfaction. Although wives in this study score somewhat lower on the AQ than husbands, their scores were high enough and had sufficient variation to find an effect. Furthermore, wives' score on the AQ correlated significantly with all the mediators, indicating that social functioning is decreased to a certain extent in women with higher scores on the AQ. Maybe other personality measures, not assessed in our study, correlate with the AQ in women but have a positive effect on their relationship functioning, thereby cancelling out the negative effects of the relationship relevant variables. Unfortunately, in the current study there were no measures that can explain how women with higher scores on the AQ compensate for lower levels of responsiveness, trust, and intimacy. Investigating this issue nevertheless seems important because if women with high levels with AQ are able to compensate deficits in their social skills, men may be able to learn to do the same.

Finally, husbands' and wives' scores on the AQ were not correlated. Unlike other personality traits (Watson et al. 2004), there seems to be no positive assortative mating for autistic traits. It has recently been suggested that autism may be the genetic result of assortative mating of two high systemisers (Baron-Cohen 2006). Our data suggest that two individuals with more autistic traits are no more likely to mate than any other two individuals. However, this may not be in conflict with the findings of Baron-Cohen. He merely notes that high systemisers' mating more often results in offspring with autism, without stating that two systemisers are more likely to mate than any other two individuals. We should emphasize that our study relies on non-clinical data, and the assortative mating hypothesis may still be valid when considering individuals with a clinical diagnosis of ASD, or even individuals within the broader phenotype of autism hypothesis (i.e. relatives of those with ASD). On the other hand, it could be speculated that our finding invalidate the assortative mating hypothesis of autism. Future research on the differentiation between multiplex families (two or more family members affected with ASD) and simplex families (one individual affected) may shed more light on this issue (Virkud et al. 2009).

\section{Directions for Future Research}

Our research gives a first indication why men with more autistic traits are less satisfied with their relationships. By identifying the mediating effects our research illuminates the link between autistic traits and relationship satisfaction. It thereby contributes to a better understanding of how autistic traits may manifest themselves in social relationships. An interesting next step would be to investigate the longitudinal aspects of autistic traits in close relationships, including the likelihood of divorce. If men with more autistic traits are less satisfied with their relationship, it seems plausible that those relationships are more likely to end in divorce. However, autistic traits are positively correlated with relationship length (Jobe and Williams White 2007). Jobe and Williams White suggested that this correlation stems from a resistance to change in individuals with many autistic traits. So, although men with more autistic traits may experience their relationships as less satisfying they might persist longer than individuals with less autistic traits because they are reluctant to change their current life situation. It therefore seems especially important to help individuals with more autistic traits to maintain satisfying relationships. Our research may help to find ways to improve relationship satisfaction of individuals with many autistic traits by identifying the skills and perceptions that mediate the link between autistic traits and relationship satisfaction.

Acknowledgments Monique Pollmann was supported by grant 40003-102 from the Netherlands Organization for Scientific Research (NWO). Catrin Finkenauer was supported by grant 452-05-322 from the Netherlands Organization for Scientific Research (NWO).

Open Access This article is distributed under the terms of the Creative Commons Attribution Noncommercial License which permits any noncommercial use, distribution, and reproduction in any medium, provided the original author(s) and source are credited. 


\section{References}

Ajzen, I. T., \& Fishbein, M. (1977). Attitude-behaviour relations: A theoretical analysis and review of empirical research. Psychological Bulletin, 84, 888-918.

American Psychiatric Association. (1994). Diagnostic and statistical manual of mental disorders (4th ed.). Washington, DC: Author.

Baron-Cohen, S. (2002). The extreme male brain theory of autism. Trends in Cognitive Sciences, 6, 248-254.

Baron-Cohen, S. (2006). The hyper-systemizing, assortative mating theory of autism. Progress in Neuro-Psychopharmacology and Biological Psychiatry, 30, 865-872.

Baron-Cohen, S., \& Wheelwright, S. (2003). The friendship questionnaire (FQ): An investigation of adults with Asperger syndrome or high functioning autism, and normal sex differences. Journal of Autism and Developmental Disorders, 33, 509-517.

Baron-Cohen, S., Wheelwright, S., Skinnner, R., \& Martin, C. E. (2001). The autism spectrum quotient (AQ): Evidence from Asperger syndrome/high functioning autism, males and females, scientists and mathematicians. Journal of Autism and Developmental Disorders, 31, 5-17.

Baumeister, R. F., \& Leary, M. R. (1995). The need to belong: Desire for interpersonal attachments as a fundamental human motivation. Psychological Bulletin, 117, 497-529.

Bauminger, N., Shulman, C., \& Agam, G. (2003). Peer interaction and loneliness in high-functioning children with autism. Journal of Autism and Developmental Disorders, 33, 489-507.

Begeer, S., Koot, H. M., Rieffe, C., Meerum Terwogt, M., \& Stegge, H. (2008). Emotional competence in children with autism: Diagnostic criteria and empirical evidence. Developmental Review, 28, 342-369.

Birnbaum, G. E., \& Reis, H. T. (2006). Women's sexual working models: An evolutionary-attachment perspective. Journal of Sex Research, 43, 328-342.

Bowlby, J. (1982). Attachment and loss: Vol. 1. Attachment (2nd ed.). New York: Basic Books.

Brennan, K. A., Clark, C. L., \& Shaver, P. R. (1998). Self-report measurement of adult attachment: An integrative overview. In J. A. Simpson \& W. S. Rholes (Eds.), Attachment theory and close relationships (pp. 46-76). New York: Guilford Press.

Capps, L., Sigman, M., \& Yirmiya, N. (1995). Self-competence and emotional understanding in high functioning children with autism. Development and Psychopathology, 7, 137-149.

Constantino, J. N., Davis, S. A., Todd, R. D., Schindler, M. K., Gross, M. M., Brophy, S. L., et al. (2003). Validation of a brief quantitative measure of autistic traits: Comparison of the social responsiveness scale with the autism diagnostic interviewrevised. Journal of Autism and Developmental Disorders, 33(4), 427-433.

Constantino, J. N., \& Todd, R. D. (2003). Autistic traits in the general population: A twin study. Archives of General Psychiatry, 60(5), $524-530$

De Martino, B., Harrison, N. A., Knafo, S., Bird, G., \& Dolan, R. J. (2008). Explaining enhanced logical consistency during decision making in autism. Journal of Neuroscience, 28, 10746-10750.

Dindia, K., \& Timmerman, L. (2003). Accomplishing romantic relationships. In J. O. Greene \& B. R. Burleson (Eds.), Handbook of communication and social interaction skills (pp. 685-721). Mahwah, NJ: Erlbaum.

Finkenauer, C. (2006). The search for inter-personal accuracy (SIPA) project: A longitudinal study among newlywed couples. The Netherlands: VU University Amsterdam. Unpublished raw data.

Finkenauer, C., Engels, R. C. M. E., Branje, S., \& Meeus, W. (2004). Disclosure and relationship satisfaction in families. Journal of Marriage and Family, 66, 195-209.
Finkenauer, C., Kerkhof, P., Righetti, F., \& Branje, S. J. T. (2009). Living together apart: Perceived concealment as signal of exclusion in marital relationships. Personality and Social Psychology Bulletin, 35, 1410-1422.

Fletcher, G. J. O., Simpson, J. A., \& Thomas, G. (2000). The measurement of perceived relationship quality components: A confirmatory factor analytic approach. Personality and Social Psychology Bulletin, 26, 340-354.

Gotham, K., Pickles, A., \& Lord, C. (2009). Standardizing ADOS scores for a measure of severity in autism spectrum disorders. Journal of Autism and Developmental Disorders, 39, 693-705.

Hellemans, H., Colson, K., Verbraeken, C., Vermeiren, R., \& Deboutte, D. (2007). Sexual behavior in high-functioning male adolescents and young adults with autism spectrum disorder. Journal of Autism and Developmental Disorders, 37, 260-269.

Henault, I. (2005). Asperger's syndrome and sexuality: From adolescence through adulthood. Philadelphia: Jessica Kingsley.

Hendrick, S. S., Hendrick, C., \& Adler, N. L. (1988). Romantic relationships: Love, satisfaction, and staying together. Journal of Personality and Social Psychology, 54, 980-988.

Hillier, A., Fish, T., Cloppert, P., \& Beversdorf, D. Q. (2007). Outcomes of a social and vocational skills support group for adolescents and young adults on the Autism Spectrum. Focus on Autism and Other Developmental Disabilities, 22, 107-115.

Hoekstra, R. A., Bartels, M., Cath, D. C., \& Boomsma, D. I. (2008). Factor structure, reliability and criterion validity of the autismspectrum quotient (AQ): A study in Dutch population and patient groups. Journal of Autism and Developmental Disorders, 38, $1555-1566$.

Hoekstra, R. A., Vinkhuyzen, A. A. E., Wheelwright, S., Bartels, M, Boomsma, D. I., Baron-Cohen, S., et al. (2009). The construction and validation of an abridged version of the Autism-Spectrum Quotient (AQ-Short) (manuscript submitted for publication).

Holmes, J. G., \& Rempel, J. K. (1989). Trust in close relationships. In C. Hendrick (Ed.), Review of personality and social psychology: Close relationships (Vol. 10, pp. 187-220). Newbury Park, CA: Sage.

Jobe, L. E., \& Williams White, S. (2007). Loneliness, social relationships, and a broader autism phenotype in college student. Personality and Individual Differences, 42, 1479-1489.

Jones, J. T., \& Cunningham, J. D. (1996). Attachment styles and other predictors of relationship satisfaction in dating couples. Personal Relationships, 3, 387-399.

Kelly, A. B., Garnett, M. S., Attwood, T., \& Peterson, C. (2008). Autism spectrum symptomatology in children: The impact of family and peer relationships. Journal of Abnormal Child Psychology, 36, 1069-1081.

Kling, K. C., Hyde, J. S., Showers, C. J., \& Buswell, B. N. (1999). Gender differences in self-esteem: A meta-analysis. Psychological Bulletin, 125, 470-500.

Lord, C. (2009). What Would "Better" Diagnoses of ASDs Look Like?" Paper presented at the International Meeting for Autism Research (IMFAR), Chicago, May 7-9.

Orsmond, G. I., Krauss, M. W., \& Seltzer, M. M. (2004). Peer relationships and social and recreational activities among adolescents and adults with autism. Journal of Autism and Developmental Disorders, 34, 245-256.

Preacher, K. J., \& Hayes, A. F. (2008). Asymptotic and resampling strategies for assessing and comparing indirect effects in multiple mediator models. Behavior Research Methods, 40, 879-891.

Reis, H. T. (2007). Steps toward the ripening of relationship science. Personal Relationships, 14, 1-23.

Reis, H. T., \& Shaver, P. (1988). Intimacy as an interpersonal process. In S. Duck, D. F. Hay, S. E. Hobfoll, W. Ickes, \& B. M. Montgomery (Eds.), Handbook of personal relationships: 
Theory, research and interventions (pp. 367-389). Oxford, England: Wiley.

Rempel, J. K., \& Holmes, J. G. (1986). How do I trust thee? Psychology Today, 20, 28-34.

Renty, J., \& Roeyers, H. (2006). Quality of life in high-functioning adults with autism spectrum disorder: The predictive value of disability and support characteristics. Autism, 10, 511-524.

Renty, J., \& Roeyers, H. (2007). Individual and marital adaptation in men with autism spectrum disorder and their spouses: The role of social support and coping strategies. Journal of Autism and Developmental Disorders, 37, 1247-1255.

Rosenberg, M. (1965). Society and the adolescent self-image. Princeton, NJ: Princeton University Press.

Rubin, E., \& Lennon, L. (2004). Challenges in social communication in Asperger syndrome and high-functioning autism. Topics in Language Disorders, 24, 271-285.

Rutgers, A. H., Bakermans-Kranenburg, M. J., Ijzendoorn, M. H., \& Berckelaer-Onnes, I. A. (2004). Autism and attachment: A metaanalytic review. Journal of Child Psychology and Psychiatry, 45, $1123-1134$.

Simpson, J. A. (2007). Psychological foundations of trust. Current Directions in Psychological Science, 16, 264-268.

Spanier, G. B. (1976). Measuring dyadic adjustment: New scales for assessing the quality of marriage and similar dyads. Journal of Marriage and the Family, 38, 15-28.
Stokes, M., Newton, N., \& Kaur, A. (2007). Stalking, and social and romantic functioning among adolescents and adults with autism spectrum disorder. Journal of Autism and Developmental Disorders, 37, 1969-1986.

Travis, L., Sigman, M., \& Ruskin, E. (2001). Links between social understanding and social behaviour in verbally able children with autism. Journal of Autism and Developmental Disorders, 31, 119-130.

Virkud, Y. V., Todd, R. D., Abbacchi, A. M., Zhang, Y., \& Constantino, J. N. (2009). Familial aggregation of quantitative autistic traits in multiplex versus simplex autism. American Journal of Medical Genetics Part B-Neuropsychiatric Genetics, $150 B, 328-334$

Watson, D., Klohnen, E. C., Casillas, A., Nus Simms, E., Haig, J., \& Berry, D. S. (2004). Match makers and deal breakers: Analyses of assortative mating in newlywed couples. Journal of Personality, 72(5), 1029-1068.

Weidle, B., Bolme, B., \& Hoeyland, A. L. (2006). Are peer support groups for adolescents with Asperger's syndrome helpful? Clinical Child Psychology and Psychiatry, 11, 45-62.

Wieselquist, J., Rusbult, C. E., Foster, C. A., \& Agnew, C. R. (1999). Commitment, pro-relationship behavior, and trust in close relationships. Journal of Personality and Social Psychology, 77, 942-966. 